Journal of Clinical Investigation

Vol. 42, No. 1,1963

\title{
THE DYNAMICS OF PULSUS ALTERNANS: ALTERNATING END-DIASTOLIC FIBER LENGTH AS A CAUSATIVE FACTOR
}

\author{
By JERE H. MITCHELL,* STANLEY J. SARNOFF, and EDMUND H. SONNENBLICK $\dagger$ \\ (From the Laboratory of Cardiovascular Physiology, National Heart Institute, Bethesda, Md.)
}

(Submitted for publication June 20, 1962 ; accepted September 8, 1962)

Pulsus alternans, first described by Traube in 1872 (1), is characterized by an alternation between weak and strong ventricular systoles with a regular rhythm (2-4). The electrocardiogram is usually normal but electrical alternans may be present $(3,5)$. Clinically, pulsus alternans most frequently occurs in the presence of myocardial disease $(3,6)$, but may also be seen in spontaneous tachycardia without any apparent myocardial abnormality $(2,7)$.

Various theories regarding the mechanism of this phenomenon have been postulated. Wenckebach believed that extracardiac factors influencing the degree of ventricular filling and therefore enddiastolic pressure and volume were the major determinants of alternation, the weak beat being initiated from a lower pressure and a smaller volume $(8,9)$. Straub's experiments led that investigator to believe that the weak beat is initiated from a smaller volume but a higher pressure and that this was attributable to incomplete metabolic recovery from the previous strong beat (10). A third view (11-15) holds that there is an alternate failure of contraction of certain myocardial segments, a view which is still current $(16,17)$.

The object of this communication is to present evidence which appears to reconcile the views of Wenckebach and Straub. It will be shown that the weak beat can be initiated from either a lower, the same, or a higher end-diastolic pressure but that, under the conditions of our experiments, the common denominator appears to be that the weak beat occurs from a shorter end-diastolic length of the contractile element. Although these findings do not rule out the possibility that an alternate failure of contraction of certain myocardial seg-

\footnotetext{
* Present Address : Established Investigator, American Heart Association, University of Texas, Southwestern Medical School, Dallas, Tex.

$\dagger$ Present Address: Department of Medicine, Columbia University, College of Physicians and Surgeons, New York, N. Y.
}

ments may occur, pulsus alternans, as observed, is explicable without implicating this mechanism. A preliminary report of these observations has been given (18).

\section{METHODS}

The data contained in this study were obtained from three experimental preparations. The first was a papillary muscle strip from the right ventricle of the dog. This was placed in a chamber containing a modified Krebs-Ringer solution and aerated with 95 per cent $\mathrm{O}_{2}$ and 5 per cent $\mathrm{CO}_{2}$. Stimulation of the muscle was provided by a Grass impulse generator. The preparation was arranged so that changes in length and tension could be controlled and recorded on a Sanborn direct-writing oscillograph (19).

In the second preparation, the dog was anesthetized with morphine, chloralose, and urethane (20). The chest was opened, and ventilation was maintained with a Starling pump. Pressures were recorded in the left atrium, left ventricle, and aorta with Statham strain gauges, and heart rate was recorded with a Waters cardiotachometer. The changes in length of a segment of left ventricular myocardium were measured by a myocardial segment length recorder $(21,22)$. All values were simultaneously recorded on an eight-channel Sanborn direct-writing oscillograph. The heart was paced from a Grass impulse generator by means of bipolar electrodes attached to the atrial appendage. In some experiments the carotid artery pressure was controlled by pump perfusion (23).

The third preparation used was an isolated, supported heart preparation in which a canine heart is isolated, but is perfused from a reservoir in which the blood is continuously exchanged with that of a donor or support dog $(24,25)$. These preparations have been described in detail in the references cited.

\section{RESULTS}

Pulsus alternans in the papillary muscle strip. Pulsus alternans was repeatedly observed in five papillary muscle preparations of the dog right ventricle. A typical example of pulsus alternans occurring in the isotonically contracting papillary muscle is shown in Figure 1, upper panel. The stimulus rate was increased from 30 to 60 per min- 
ute just before A. Pulsus alternans appeared at this increased rate. The weak beat $(\mathrm{B})$ occurred from a shorter initial length than did the strong beat $(\mathrm{C})$. As the increased rate of stimulation was continued and the increased myocardial contractility developed, as is usual when the rate is elevated $(25,26)$, the intensity of the alternans abated. This diminution in the intensity of the pulsus alternans was accompanied by a gradual increase of initial length before the weak beat. That an increased contractility had taken place during the period of higher frequency was indicated by the greater shortening in the first few beats after returning to the lower rate at $\mathrm{D}$.

Pulsus alternans is also seen in the isometrically contracting papillary muscle. Examples of this are shown in Figure 1, middle and lower panels. In Figure 1, middle panel, the rate of stimulation was increased from 40 to 80 per minute at $\mathrm{A}$; from the same initial tension and external length, an increase in developed tension was established after several beats (Bowditch staircase). At B, the rate was decreased from 80 to 40 per minute, and there was a slow decrease in the developed tension. At $\mathrm{C}$, the rate of stimulation was increased from 40 to 120 per minute and pulsus alternans occurred. The initial tension was higher before the weak beat. After several beats, the pulsus alternans almost disappeared, as did the alternation of initial tension. At $\mathrm{D}$, the rate was decreased from 120 to 40 per minute and there was a slow decrease in the developed tension. When compared with the control values at the lower rate, the increased developed tension just after B and D is an exhibition of the increase in contractility which is induced during periods of increased stimulation rate as is seen in the intact isolated heart $(25,26)$.

Pulsus alternans in the isometrically contracting papillary muscle is also shown in Figure 1, lower panel. The left portion of the tracing (section 1) was recorded at higher gain for emphasis on initial tension. The right portion of the tracing (section 2 ) was recorded at lower gain for emphasis on de-
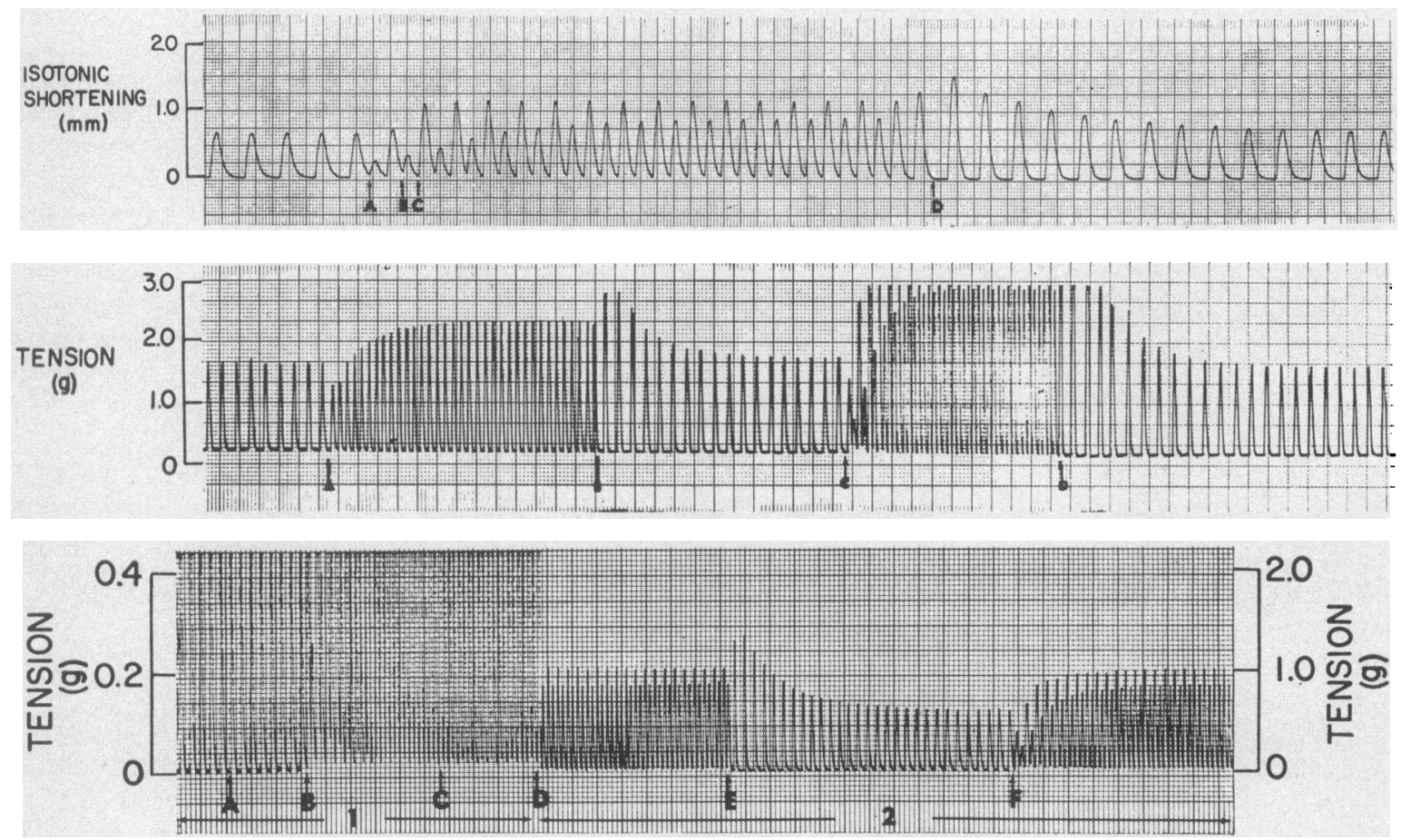

Fig. 1. Upper: Isotonic contraction of dog papillary muscle. Pre-load is $1.0 \mathrm{~g}$; temperature is $25^{\circ} \mathrm{C}$; isotonic shortening in millimeters $(\mathrm{mm})$ shown on left; paper speed $=5.0 \mathrm{~mm}$ per second. MiddLE: Temperature is $25^{\circ} \mathrm{C}$; isometric tension in grams $(\mathrm{g})$ shown on left; paper speed $=2.5 \mathrm{~mm}$ per second. Lower: Temperature is $24^{\circ} \mathrm{C}$; for section 1, isometric tension in grams ( $\mathrm{g}$ ) shown at left, and for section 2, isometric tension in grams ( $\mathrm{g}$ ) shown at right; paper speed $=1.0 \mathrm{~mm}$ per second. 


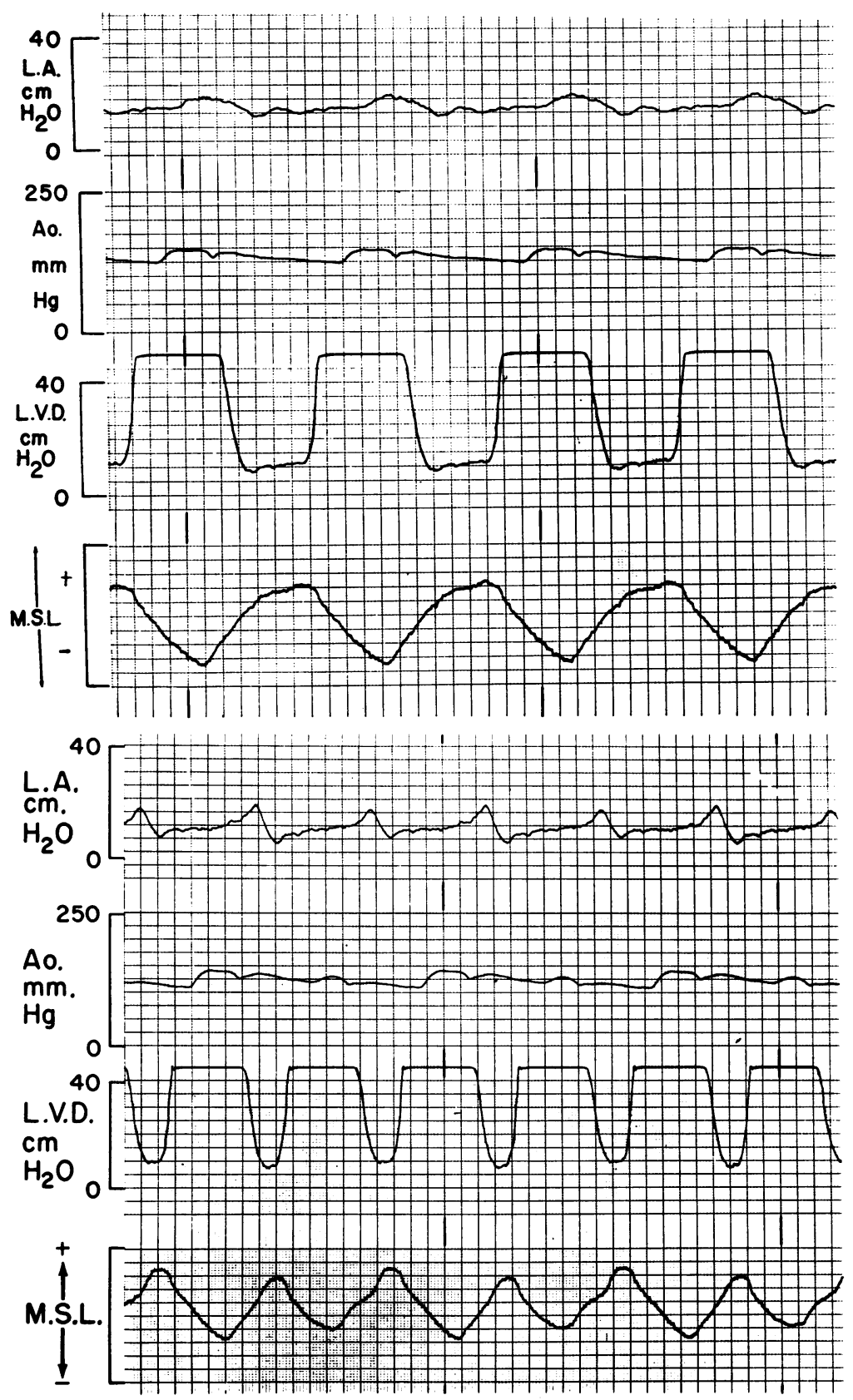

Fig. 2. Upper: In situ heart preparation without pUlsus alternans. L.A. = left atrial pressure; Ao = aortic pressure; L.V.D. = left ventricular diastolic pressure; M.S.L. = changes in myocardial segment length, $+=$ elongation, and $-=$ shortening. Paper speed $=100 \mathrm{~mm}$ per second.

Lower: Pulses alternans in the in situ heart preparation. Symbols as in Figure 2, upper. Paper speed $=100 \mathrm{~mm}$ per second.

veloped tension. The rate was 30 during $\mathrm{A}$ and changed to 60 at $\mathrm{B}$; initial tension alternation occurred during $\mathrm{C}$. The gain was decreased at $\mathrm{D}$ and shows the alternation of developed tension.
The rate was then returned to 30 at $\mathrm{E}$ and was re-elevated to 60 at $\mathrm{F}$. Alternation of developed tension was present at the higher rate and not at the lower rate. 
It was consistently observed throughout the experiments of the types shown above that small differences in initial tension (Figure 1, middle and lower panels) or in initial length (Figure 1, upper panel) would produce marked alternation of either tension development or shortening. Worthy of note is the fact that the weak beat always originated from the higher initial tension with external length constant in the isometrically contracting preparations and from the shorter external length with tension constant in the isotonically contracting preparations.

Pulsus alternans in the left ventricle. Certain hemodynamic findings in the same heart without and with pulsus alternans are shown in Figure 2, which is representative of those observed in the five intact heart preparations studied. In Figure 2 , upper panel, pulsus alternans was not present. The heart rate was 115 per minute, and the total cardiac cycle time was $520 \mathrm{msec}$. The duration of ventricular systole (from beginning of the rise in left ventricular pressure until aortic incisura) for each beat was $250 \mathrm{msec}$. The duration of ventricular diastole (from beginning of aorta incisura to the rise in left ventricular pressure) was 270 msec. For each beat, the left ventricular end-diastolic pressure, end-diastolic myocardial segment length, and end-systolic segment length were the same. In Figure 2, lower panel, at a heart rate of 175 per minute, pulsus alternans was present. The total cardiac cycle time was 343 msec. The duration of ventricular systole for the strong beat was $238 \mathrm{msec}$, and that for the weak beat $220 \mathrm{msec}$. The duration of ventricular diastole was $123 \mathrm{msec}$ before the strong beat and $105 \mathrm{msec}$ before the weak beat. The weak beat occurred from a 2 $\mathrm{cm} \mathrm{H}_{2} \mathrm{O}$ lower, left ventricular, end-diastolic pressure and a shorter, left ventricular, end-diastolic, myocardial segment length than did the strong beat. The left ventricular, end-systolic, myocardial segment length was longer after the weak beat than after the strong beat. The atrial $a$ wave was higher before the weak beat than before the strong beat.

Three different types of pulsus alternans in the same intact heart preparation are shown in Figure 3. The heart rate was 240 per minute, and the total cycle time was $250 \mathrm{msec}$ in all three examples. In the left panel the duration of ventricular systole for the strong beat was $200 \mathrm{msec}$ and that for the weak beat was $180 \mathrm{msec}$. The duration of ventricular diastole was $70 \mathrm{msec}$ before the strong beat and before the weak beat was $50 \mathrm{msec}$. The weak beat occurred from a $2 \mathrm{~cm} \mathrm{H}_{2} \mathrm{O}$ lower, ventricular, end-diastolic pressure. This is the same type of pulsus alternans as seen in Figure 2, lower panel. In the middle panel, the weak and strong ventricular beats occurred from the same ventricular end-diastolic pressure. The duration of ventricular systole for the strong beat was 190
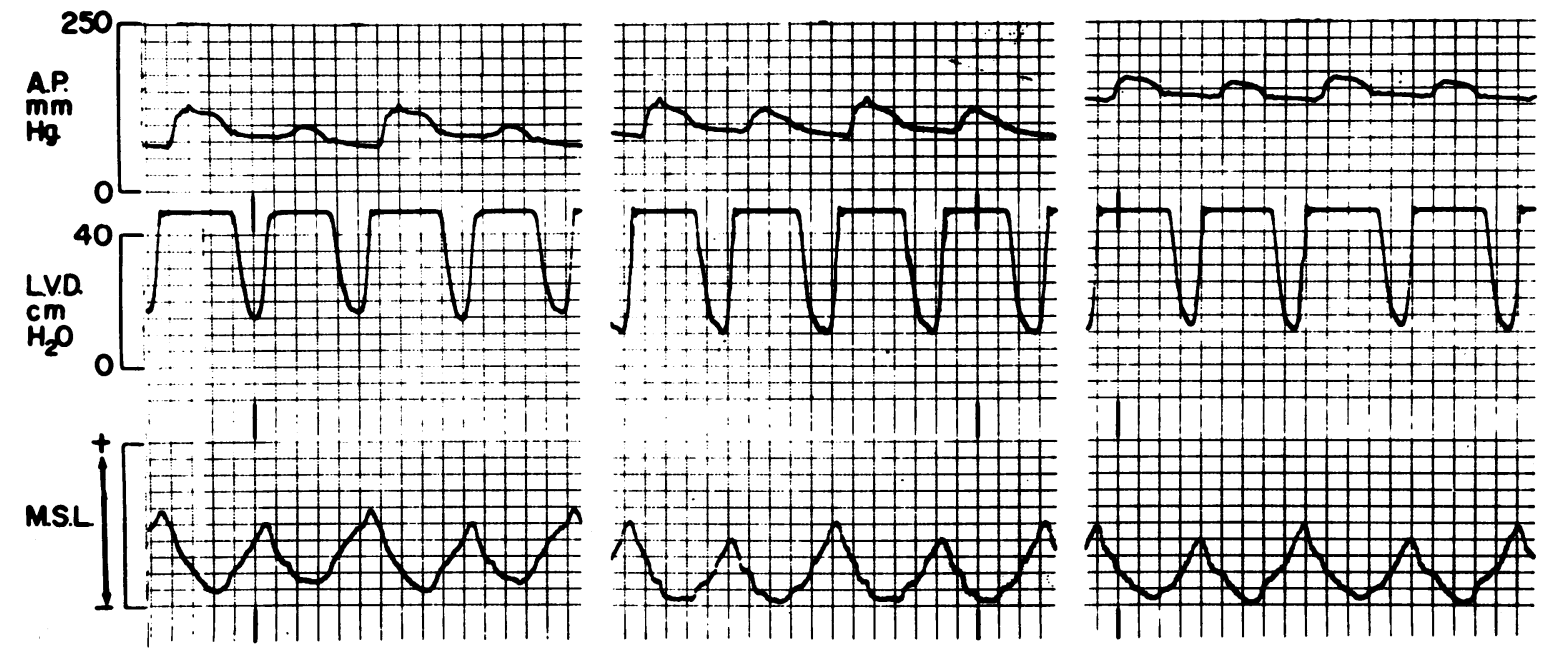

Fig. 3. Pulsus alterans in the in situ heart preparations. A.P. = aortic pressure; L.V.D. = left ventricular diastolic pressure; M.S.L. $=$ changes in myocardial segment length, $+=$ elongation, and $-=$ shortening. Paper speed $=100 \mathrm{~mm}$ per second. 

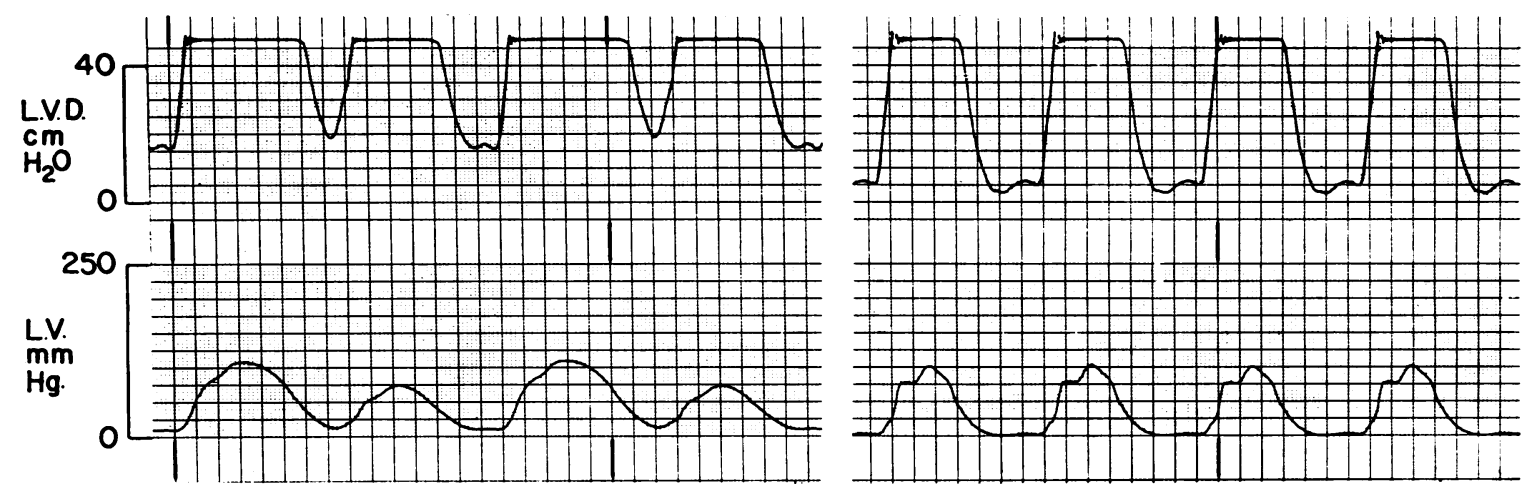

Fig. 4. Pllsus alternans in the isolated, supported heart with controlled coronary flow. L.V.D. = left ventricular diastolic pressure from 0 to $40 \mathrm{~cm} \mathrm{H} \mathrm{H}_{2} \mathrm{O}$. L.V. = left ventricular pressure for 0 to $250 \mathrm{~mm} \mathrm{Hg}$. In the left panel, pulsus alternans is present. In right panel, during the constant infusion of norepinephrine, pulsus alternans is not present. Paper speed $=100 \mathrm{~mm}$ per second.

msec and that for the weak beat was $180 \mathrm{msec}$. The duration of ventricular diastole before the strong beat was $70 \mathrm{msec}$ and that before the weak beat was $60 \mathrm{msec}$. In the right panel, the duration of ventricular systole for the strong beat was 190 msec and that for the weak beat was $175 \mathrm{msec}$. The duration of ventricular diastole before the strong beat was $75 \mathrm{msec}$ and that before the weak beat was $60 \mathrm{msec}$. In this instance, the weak beat occurred from a $2 \mathrm{~cm} \mathrm{H}_{2} \mathrm{O}$ higher, ventricular, end-diastolic pressure. Whether ventricular enddiastolic pressure was lower, the same, or higher, before the weak beat, the diastolic interval and the ventricular end-diastolic, myocardial segment length were always shorter before the weak beat.

The effect of increasing ventricular contractility on pulsus alternans. Pulsus alternans was repeatedly abolished in three isolated, supported
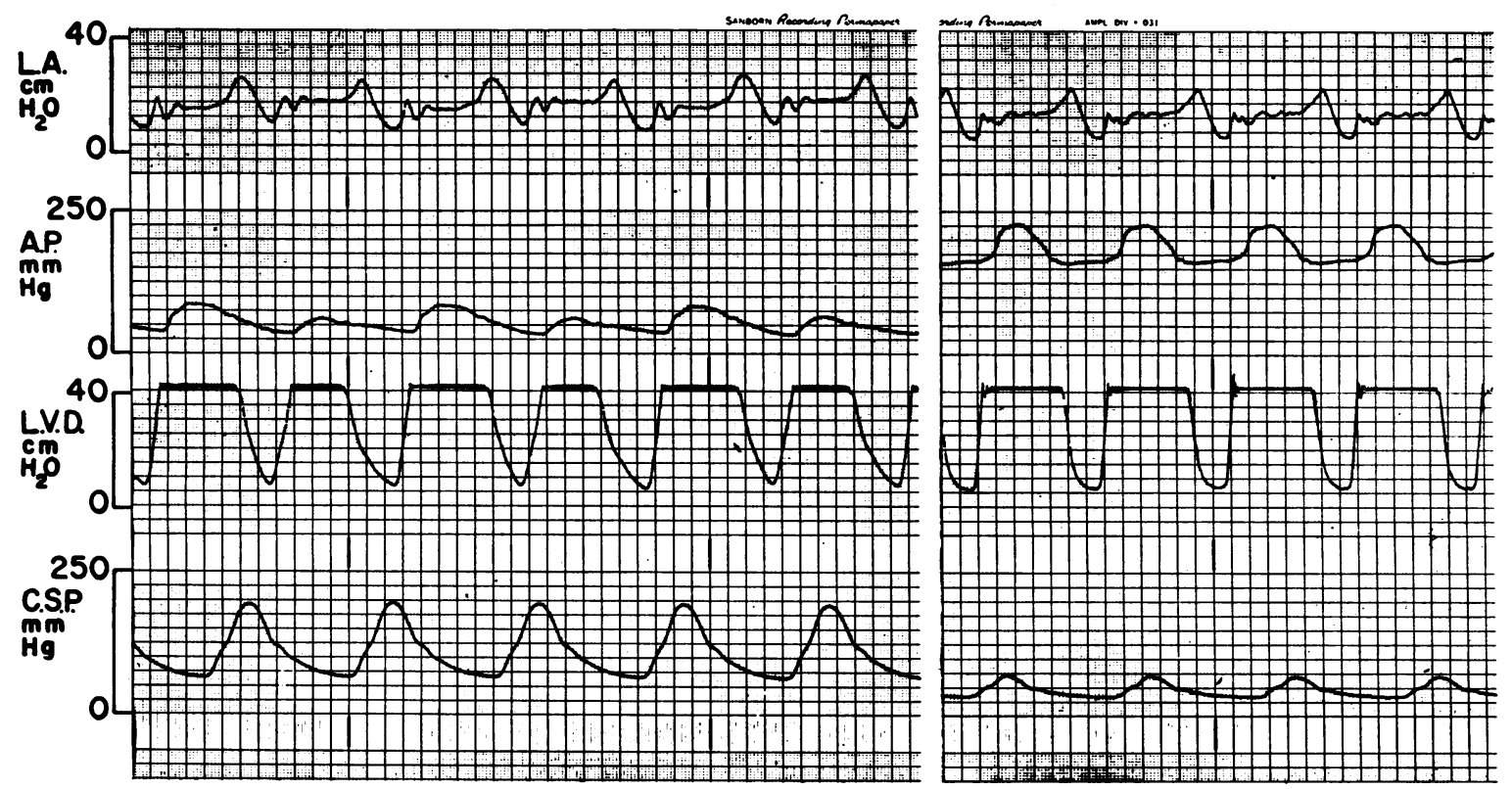

Fig. 5. In situ heart preparation with controlled carotid artery pressure. L.A. = left atrial pressure; A.P. $=$ aortic pressure $;$ L.V.D. = left ventricular diastolic pressure; C.S.P. = carotid sinus pressure. Heart rate held constant by atrial pacing. In left panel, during high carotid sinus pressure, pulsus alternans is present. Aortic flow $=1,200 \mathrm{ml}$ per minute. In right panel, when the carotid sinus pressure is low, pulsus alternans is not present. Aortic flow $=2,400 \mathrm{ml}$ per minute. Paper speed $=100 \mathrm{~mm}$ per second. 
heart preparations by the continuous infusion of norepinephrine. An example of this is shown in Figure 4, which was obtained from an isolated, supported heart with constant left coronary flow. Pulsus alternans was present in the left panel. The total cardiac cycle time for each beat was 375 msec. The duration of ventricular systole for the strong beat was $270 \mathrm{msec}$ and that for the weak beat was $200 \mathrm{msec}$. The duration of ventricular diastole was $175 \mathrm{msec}$ before the strong beat and $105 \mathrm{msec}$ before the weak beat. This was the type of pulsus alternans in which the weak beat occurred from a higher ventricular, end-diastolic pressure than did the strong beat. The ventricle was clearly not completely relaxed at the end of diastole before the weak beat. The tracing in the right panel was obtained during the continuous infusion of norepinephrine, and pulsus alternans disappeared. Again, the total cardiac cycle time was $375 \mathrm{msec}$, but the duration of ventricular systole was $180 \mathrm{msec}$ and the duration of ventricular diastole was $195 \mathrm{msec}$ for each beat. The increase in the rate of development of tension and consequent shortening of systole induced by norepinephrine allowed for an adequate diastolic interval after the strong beat.

Pulsus alternans was induced and abolished by varying carotid sinus pressure, an intervention known to modify ventricular contractility (23), in three intact heart preparations. An example of this is shown in Figure 5. Heart rate was held constant by atrial pacing. In the left panel, during high carotid sinus pressure, pulsus alternans was present. For each beat, the total cardiac cycle time was $345 \mathrm{msec}$. The duration of ventricular systole for the strong beat was $235 \mathrm{msec}$, and that for the weak beat was $200 \mathrm{msec}$. The duration of ventricular diastole before the strong beat was $145 \mathrm{msec}$, and $110 \mathrm{msec}$ before the weak beat. The weak beat occurred from a slightly higher ventricular end-diastolic pressure than did the strong beat. In the right panel, during low carotid sinus pressure and the consequent reflex sympathetic stimulation (23), pulsus alternans disappeared. Aortic pressure and flow increased. Again the total cardiac cycle time was $345 \mathrm{msec}$, but the duration of ventricular systole was 225 msec, and the duration of ventricular diastole was $120 \mathrm{msec}$ for each beat.

\section{DISCUSSION}

There is nothing in the above data which makes it possible to decide whether or not an alternate failure of contraction of certain myocardial segments occurs during pulsus alternans. The data make it possible, however, to introduce a unifying element in the conceptual approach to this problem without resort to this unknown variable. It is clear from the above data that in pulsus alternans the weak beat can occur from a lower, the same, or a higher ventricular end-diastolic pressure. What appears to be a common denominator is that the initial fiber length is, at least under the conditions of these experiments, always shorter before the weak beat.

At any particular moment in time, the relation between pressure and volume (or fiber length) in the ventricle will be determined by the compliance of the ventricular myocardium and the volume of blood it contains. These two variables can be held to account reasonably completely for the observed phenomena. In a ventricle which has not yet lost the increased stiffness it acquired during the preceding systole at the time of the subsequent systole, the pressure in it will be higher for any given end-diastolic volume or fiber length than if relaxation had been complete. In a ventricle which is completely relaxed, the end-diastolic volume and fiber length will be importantly influenced by small absolute changes in the time available for inflow if the diastolic period available for inflow is short, as is usually the case with pulsus alternans.

Lendrum, Feinberg, Boyd, and Katz (27) and Siegel and Sonnenblick (28) have recently demonstrated pulsus alternans in an isovolumic ventricle. The former group were apparently impressed by the occurrence of the ventricular "alternans phenomenon unassociated with changes in fiber length." Siegel and Sonnenblick made two observations of note. Using their index of changes in the basic state of the myocardium (28), they found that the myocardium did not appear to alternate its basic state in the weak and strong beats. Further, using high gain for recording ventricular diastolic pressures, they found that the weak beat in the alternating isovolumic ventricle consistently originated from a higher end-diastolic pressure. 
Relevant to the finding of these two groups are the data in the papillary muscle experiments shown above (Figure 1). The explanation of the alternating shortening in the isotonically contracting papillary muscle (Figure 1, upper) is clear: the weak contraction originated from a shorter initial fiber length. In the isometrically contracting papillary muscle, in which the external length was fixed. the weak contraction originated from a higher initial tension, that is to say, from a state of incomplete relaxation. There is no way at present of assessing the extent to which a muscle strip which is fixed at both ends has an internal geometric rearrangement which influences effective muscle fiber length during the relaxation phase. Further, there may be dead tissue at or near either end of the muscle at the point of fixation which introduces a compliance of unknown parameters into the over-all system. Most important. however, is the possibility that, although the external length is fixed, a muscle in which the tension has not completely subsided almost certainly has a different distribution of stretch in its internal elements, i.e.. contractile element and series elastic $(29,30)$, than is the case when the resting tension is fully achieved. In the former case, when the resting tension is higher, the length of the contractile element can confidently be expected to be less than in the latter case when the resting tension is lower. Thus the shorter length of the contractile element which is present before the weak beat accounts for the diminished force of contraction.

The contractility of the ventricular myocardium appears to be an important element in determining whether or not pulsus alternans will occur. This is consonant with the observation that this phenomenon is most often seen in the diseased heart $(3,6)$. In the present study, pulsus alternans was found to occur when the continuous level of myocardial contractility was such that, at a given imposed heart rate, stroke volume, and aortic pressure, there was not an adequate time for diastole after the strong beat. The inadequate diastolic time after the strong beat did not allow a comparable period either for complete relaxation, or filling, or both. When ventricular contractility was increased, systole shortened, and the diastolic pe- riod thereby prolonged (Figures 4 and 5), pulsus alternans was abolished.

These considerations reconcile the views of Straub, who felt that the weak beat always originated from a higher end-diastolic pressure because of an inadequate period for ventricular relaxation (10), and those of Wenckebach, who felt that the weak beat always originated from a lower enddiastolic pressure because of less filling $(8,9)$. The above represents a synthesis of these views, since it was shown that pulsus alternans can occur from either a lower or higher end-diastolic pressure and further, that as both Wenckebach and Straub would agree, the weak beat is initiated from a shorter end-diastolic fiber length. It is not necessary to postulate a fractionate deletion of contractions during the weak beat in order to explain the observed findings.

Ferrer, Harvey, Cournand, and Richards (4) suggested that a variation in end-diastolic fiber length might not be a relevant mechanism. In a patient with mild right ventricular alternans, they did not feel that they observed substantial alternations in end-diastolic pressure. However, perusal of Figure 11 of their paper (the only tracing which was obtained during breath-holding) shows that the strong beat was initiated from a right ventricular, end-diastolic pressure which was several centimeters of $\mathrm{H}_{2} \mathrm{O}$ higher than that which was present before the weak beat. This is most marked in the first four of the six beats of their tracing, and it is in these beats that the alternation of right ventricular systolic pressure is greatest. A change of ventricular end-diastolic pressure of one or two $\mathrm{cm}$ $\mathrm{H}_{2} \mathrm{O}$ can make a substantial difference in the enddiastolic fiber length and the stroke work of the subsequent beat $(21,31)$. This interpretation of their data is strengthened by the recent observations of Gleason and Braunwald, who studied serial volume changes with biplane selective angiography during four consecutive beats in a patient with left ventricular alternans (32). They not only found that the left ventricular volume was smaller before the weak beat, but that there was a good correlation between the end-diastolic volume and the subsequent volume ejected.

Katz and Feil postulated that end-systolic volume is smaller after the strong beat and that alternation of the diastolic period of filling was not 
a relevant variable (33). That end-systolic volume is smaller after the strong beat was demonstrated by Straub (10) and by Wiggers (34) with biventricular oncometry, in the patient of Gleason and Braunwald (32), and by the segment length tracings shown above. It is self-evident that, if end-systolic volume is smaller and the inflow period and gradient the same after the strong beat, end-diastolic pressure and fiber length will be lower before the weak beat. This must be considered a relevant variable in pulsus alternans, but the tracings shown above make it unwise to exclude variations in the time available for ventricular relaxation and filling.

\section{SUM MARY}

The data presented above and a consideration of the references cited seem to make possible a conceptual simplification of the phenomenon of pulsus alternans. The available evidence indicates that the weak beat is initiated from a shorter enddiastolic fiber length than is the strong beat, whether the end-diastolic pressure is lower, the same, or higher. This can be brought about by an inadequate diastolic period for ventricular relaxation, ventricular filling, or both, relative to the inflow volume required to produce any given enddiastolic fiber length from any given end-systolic volume. In this study, pulsus alternans occurred when the continuous level of myocardial contractility was not sufficient for a given imposed heart rate, stroke volume, and aortic pressure to allow an adequate time for diastole before the weak beat. Pulsus alternans was abolished when an increase in myocardial contractility was induced by norepinephrine infusion or by reflex cardiac sympathetic nerve stimulation.

\section{ACKNOWLEDGMENT}

We gratefully acknowledge the valuable technical assistance of Mrs. Carrie Scott and Mr. Frank Perry.

\section{REFERENCES}

1. Traube, L. Ein Fall von Pulsus bigeminus. Ber1. klin. Wschr. 1872, 9, 185.

2. Lewis, T. The Mechanism and Graphic Registration of the Heart Beat. London, Shaw and Sons, 1925.

3. Friedberg, C. K. Diseases of the Heart, 2nd ed. Philadelphia, W. B. Saunders Co., 1956.

4. Ferrer, M. I., Harvey, R. M., Cournand, A., and Richards, D. W. Cardiocirculatory studies in pul- sus alternans of the systemic and pulmonary circulations. Circulation 1956, 14, 163.

5. Kalter, H. H., and Grishman, A. The electrical alternans. J. Mt. Sinai Hosp. 1943, 10, 459.

6. Blumberger, K. Untersuchungen über die Dynamik des Herzens beim Herzalternans. Arch. Kreisl.Forsch. 1953, 20, 25.

7. Saunders, D. E., Jr., and Ord, J. W. The hemodynamic effects of paroxysmal supraventricular tachycardia in patients with the Wolff-Parkinson White syndrome. Amer. J. Cardiol. 1962, 9, 223.

8. Wenckebach, K. F. Zur Analyse des unregelmässigen Pulses. IV. Ueber den Pulsus alternans. Z. klin. Med. 1910, 44, 218.

9. Wenckebach, K. F. Die unregelmässige Herztätigkeit und ihre klinische Bedeutung. Berlin, Englemann, 1914.

10. Straub, H. Dynamik des Herzalternans. Arch. klin. Med., 1917, 123, 403.

11. Gaskell, W. H. On the rhythm of the heart of the frog, and on the nature of the action of the vagus nerve. Phil. Trans. B. 1882, 173, 993.

12. Hering, H. E. Experimentelle Studien an Säugethieren über das Elektrocardiogramm II. Z. exp. Path. Ther. 1909, 7, 363.

13. Mines, G. R. On pulsus alternans. Proc. Cambridge phil. Soc. 1913, 17, 34.

14. Green, H. D. The nature of ventricular alternation resulting from reduced coronary blood flow. Amer. J. Physiol. 1935-36, 114, 407.

15. Wiggers, C. J. Circulatory Dynamics. New York, Grune and Stratton, 1952.

16. Wiggers, C. J. Reminiscences and Adventures in Circulation Research. New York, Grune and Stratton, 1958.

17. Corday, E., and Irving, D. W. Disturbances of Heart Rate, Rhythm, and Conduction. Philadelphia, W. B. Saunders Co., 1961.

18. Mitchell, J. H., Sonnenblick, E. H., and Sarnoff, S. J. Pulsus alternans: alternating end diastolic fiber length as a causative factor. Fed. Proc. 1961, 20, 129.

19. Sonnenblick, E. H. Force-velocity relations in mammalian heart muscle. Amer. J. Physiol. 1962, 202, 931.

20. Sarnoff, S. J., Brockman, S. K., Gilmore, J. P., Linden, R. J., and Mitchell, J. H. Regulation of ventricular contraction. Influence of cardiac sympathetic and vagal nerve stimulation on atrial and ventricular dynamics. Circulat. Res., 1960, 8, 1108.

21. Linden, R. J., and Mitchell, J. H. Relation between left ventricular diastolic pressure and myocardial segment length and observations on the contribution of atrial systole. Circulat. Res., 1960, 8, 1092.

22. Mitchell, J. H., Linden, R. J., and Sarnoff, S. J. Influence of cardiac sympathetic and vagal nerve stimulation on the relation between left ventricu- 
lar diastolic pressure and myocardial segment length. Circulat. Res. 1960, 8, 1100.

23. Sarnoff, S. J., Gilmore, J. P., Brockman, S. K., Mitchell, J. H., and Linden, R. J. Regulation of ventricular contraction by the carotid sinus. Its effect on atrial and ventricular dynamics. Circulat. Res. 1960, 8, 1123.

24. Sarnoff, S. J., Case, R. B., Welch, G. H., Jr., Braunwald, E., and Stainsby, W. N. Performance characteristics and oxygen debt in a nonfailing, metabolically supported, isolated heart preparation. Amer. J. Physiol. 1958, 192, 141.

25. Sarnoff, S. J., Mitchell, J. H., Gilmore, J. P., and Remensnyder, J. P. Homeometric autoregulation in the heart. Circulat. Res. 1960, 8, 1077.

26. Sarnoff, S. J., Gilmore, J. P., Mitchell, J. H., and Remensnyder, J. P. Potassium balance changes in the heart resulting from acetyl strophanthidin and homeometric autoregulation. In preparation.

27. Lendrum, B., Feinberg, H., Boyd, E., and Katz, L. N. Rhythm effects on contractility of the beating isovolumic left ventricle. Amer. J. Physiol. 1960, 199, 1115.
28. Siegel, J. H., and Sonnenblick, E. H. A dynamic index characterizing the basic state of the myocardium. Circulat. Res. In press.

29. Hill, A. V. The heat of shortening and the dynamic constants of muscle. Proc. roy. Soc. B. 1938, 126, 136.

30. Hill, A. V. The abrupt transition from rest to activity in muscle. Proc. roy. Soc. B 1949, 136, 399.

31. Sarnoff, S. J., and Mitchell, J. H. The regulation of the performance of the heart. Amer. J. Med. $1961,30,747$.

32. Gleason, W. L., and Braunwald, E. Studies on Starling's law of the heart. VI. Relationships between left ventricular end-diastolic volume and stroke volume in man with observations on the mechanism of pulsus alternans. Circulation 1962, $25,841$.

33. Katz, L. N., and Feil, H. S. Clinical observations on the dynamics of ventricular systole. IV. Pulsus alternans. Amer. J. med. Sci. 1937, 194, 601.

34. Wiggers, C. J. The cause of temporary ventricular alternation following a long diastolic pause. Proc. Soc. exp. Biol. (N. Y.) 1927, 24, 386. 